Nunt. Antiquus, Belo Horizonte, v. 14, n. 2, p. 217-240, 2018

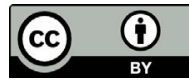

\title{
O espaço heterotópico da peregrinação - uma análise heterotopológica dos caminhos de Santiago
}

\author{
The Heterotopical Space of Pilgrimage - \\ An Heterotopological Analysis of Caminos de Santiago
}

\author{
Victor Hermann Mendes Pena \\ Universidade Federal de Minas Gerais, Belo Horizonte, Minas Gerais / Brasil \\ hermann.victor@gmail.com
}

Resumo: O objetivo deste artigo é elaborar uma análise heterotópica da prática de peregrinação religiosa na Idade Média. Para tal, iremos: rever o conceito de heterotopia, concebido pelo filósofo Michel Foucault, e analisar alguns aspectos da peregrinação através da teoria da heterotopia (utilizando como recorte o entrecho do Purgatório da Divina comédia, de Dante, relatos de milagres no caminho de Compostela e estudos acerca da rota jacobeia). Por fim, buscaremos examinar a aparição tópica da peregrinação na obra História da loucura na Idade Clássica, e de que modo uma heterotopologia da peregrinação pode elucidar alguns aspectos do mundo atual - buscando, assim, destacar a importância de uma abordagem heterotópica desse fenômeno para a história do espaço. Palavras-chave: heterotopia; peregrinação; Caminhos de Santiago.

Abstract: The purpose of this article is to elaborate an Heterotopic comprehension of the practice of religious pilgrimage in the Middle Age. For this, we are going to review the concept of Heterotopia, conceived by the philosopher Michel Foucault, and to analyze some aspects of pilgrimaging through the theory of Heterotopia (we will use the plot of the Purgatorio, second part of the Divine Comedy by Dante Alighieri, the descriptions of certain miracles in the pilgrimage route to Compostela, and some studies on the Jacobean route as the bases for these analyses). We will also study the importance of the pilgrimage in the work Madness and Civilization, by the same author. Through these we shall outline the importance of a Heterotopic view of pilgrimaging to the history of space.

Keywords: Heterotopy; pilgrimage; Caminos de Santiago. 


\section{Introdução}

A Europa nasceu no caminho de peregrinação a Santiago. (Goethe $)^{1}$

O objetivo deste artigo é elaborar uma análise heterotópica da prática de peregrinação religiosa na Idade Média. O conceito de heterotopia fora concebido pelo filósofo Michel Foucault tendo em vista uma reflexão sobre a experiência do espaço ao longo da história. Segundo o autor, seria possível delinear três grandes experiências do espaço: de localização, na Idade Média; de extensão, na Idade Clássica; e de posicionamento, na era contemporânea. Heterotopias são todos os lugares concretos que, em uma determinada experiência de espaço, guardam relação com todos os demais posicionamentos possíveis em uma dada cultura, acolhendoos, seja através da representação, da contestação ou da inversão. Nossa hipótese consiste em considerar o caminho de peregrinação como espaço heterotópico. Para tal, iremos analisar a peregrinação no Purgatório, da Divina comédia de Dante, os relatos de milagres no caminho de Compostela, bem como estudos históricos acerca da rota jacobeia.

\section{0 espaço de localização}

O filósofo Michel Foucault, em seu ensaio intitulado "Outros Espaços" (2003) - escrito em 1967 e publicado pela primeira vez em 1984 -, destaca a importância do espaço para a história contemporânea. Segundo o autor, a ênfase que o século XIX dera ao tempo como grande motor da história teria sido substituída por uma época do espaço:

[...] estamos na época do simultâneo, estamos na época da justaposição, do próximo e do longínquo, do lado a lado, do disperso. Estamos em um momento em que o mundo se experimenta, acredito, menos como uma grande via que se desenvolveria através

${ }^{1}$ ROSZAK, 2015, p. 648. Tradução minha. 
dos tempos do que como uma rede que religa pontos e que entrecruza sua trama. (FOUCAULT, 2003, p. 411).

O espaço suscitaria uma nova experiência - seja do tempo, seja do ambiente - em forma de rede, no interior da qual se evocam questões de estocagem, circulação, localização e classificação, isto é, questões acerca da configuração e distribuição dos elementos sobre o espaço. Entretanto, seria errôneo, segundo Foucault, considerar que somente nossa época teria desenvolvido uma compreensão crítica do espaço. Haveria toda uma história do espaço na experiência ocidental que deve, agora, ser levada em consideração.

Conforme já destacado, seria possível, segundo o autor, perceber na história três grandes experiências do espaço: o espaço de localização, da Idade Média; o espaço de extensão, da Idade Clássica (termo utilizado por Foucault para o período que segue do século XVII ao XIX); e o espaço de posicionamento, característico da época contemporânea. No presente artigo, nosso enfoque será o espaço medieval.

Segundo Foucault, o espaço de localização medieval seria, essencialmente, um conjunto hierarquizado de lugares opostos e entrecruzados: lugares sagrados e profanos, urbanos e rurais, fechados e seguros em oposição a abertos e desprotegidos, e, ainda, a longa cadeia de lugares opostos no interior de uma concepção cosmológica de mundo - que estabelece em oposição os lugares supracelestes, passando pelos celestes e, por fim, os terrestres. No interior desse conjunto rigidamente hierarquizado se compreenderiam a localização de todos os seres e coisas: desde aqueles adaptados naturalmente aos lugares onde repousam; até aqueles violentamente deslocados por força mágica ou divina.

Para aprofundar a noção foucaultiana de espaço de localização, apenas brevemente delineada em seu ensaio, recorremos à complexa topografia da Divina comédia, de Dante Alighieri - em especial, o entrecho do Purgatório. A escolha baseia-se no fato de que, segundo o pesquisador Célio Antônio Sardagna, o Purgatório seria uma espécie de "novidade" da obra de Dante em relação à mitologia grega, onde haveria apenas o reino dos deuses e dos mortos. A travessia do poeta-peregrino no Purgatório nos servirá para elaborar algumas noções de deslocamento no interior do espaço de localização medieval. 
Sardagna (2006, p. 17) aponta para a "geografia particular desse reino [...], um local montanhoso que se ergue no hemisfério meridional da Terra, nos antípodas de Jerusalém". Com efeito, no antepurgatório, a parte mais baixa da montanha ainda envolta pela atmosfera terrestre, conservam-se as almas em estado de penitência, aquelas ainda consideradas indignas de serem admitidas nas partes mais altas. O Purgatório, por sua vez, está localizado no cume da montanha e é acessível somente através de uma porta guardada por um anjo e um estreito caminho escavado na rocha, dividido em sete patamares concêntricos sobrepostos cujos raios diminuem de acordo com a altura. Os patamares correspondem aos sete pecados capitais, e as almas, ao galgá-los, purgam-se de seus vícios capitais.

Segundo Sardagna, o Purgatório, em contraposição ao Inferno e ao Paraíso, seria mais próximo da experiência terrestre. No trecho destacado, o poeta-peregrino, que havia perdido a noção de tempo no Inferno, redescobre a temporalidade no Purgatório, engendrada através da luz e das estrelas:

\footnotetext{
Nesse caminho pouco luminoso entramos por voltar ao claro mundo; e sem cuidar de ter algum repouso, subimos, antes ele e eu segundo, tanto que eu vi enfim as cousas belas que tem o céu, por um buraco ao fundo; e saímos voltando a ver estrelas.
}

(DANTE citado por SARDAGNA, 2006, p. 20)

Para o crítico, o poeta-peregrino, ao alcançar o segundo reino do Purgatório, sentiria uma libertação física com a retomada dos sentidos, em especial o olhar. Sentiria, também, um retorno à experiência da temporalidade do dia e de uma corporeidade terrestre e espiritual, através da libertação do mundo dos pecados.

É, portanto, no entrecho do Purgatório que o sentido de peregrinação adquire seu sentido mais pleno, na medida em que experimenta a transmutação das qualidades sensíveis da vida terrena - a luz, o tempo, a beleza e o caminho visível - em um plano de ascendência divina. 
[...] o segundo reino é o que mais se aproxima da vida real, e por isso é a parte mais moderna da visão que é expressa no poema. Aqui as almas estão a caminho, peregrinas como sobre a terra, possuídas por uma temporalidade medida pela imaginação do peregrino. (FRECCERO citado por SARDAGNA, 2006, p. 20).

O poeta peregrina sobre a geografia da Terra, porém seu destino é o Paraíso, reino de luz e vida eterna. O poeta-peregrino somente logrará encaminhar-se para os céus mediante um progressivo afastamento da vida cotidiana e seus vícios capitais. O espaço onde se realiza a peregrinação adequa-se à noção de localização, concebida por Foucault: é composto de uma longa cadeia de lugares opostos por uma concepção cosmológica (Inferno, Purgatório, Paraíso) e é rigidamente hierarquizado (antepurgatório, purgatório; os degraus dos sete pecados capitais). A peregrinação introduz, no espaço de localização, o deslocamento, na medida em que o peregrino busca, através de sua caminhada, a rota mais piedosa de purificação rumo ao Paraíso.

Nesse sentido, pode-se dizer que a obra de Dante elabora uma espécie de lógica do deslocamento no interior do espaço de localização. É regida, sobretudo, pela lei do contrapasso, cujas caracteriscas gerais seriam:

O contrapasso prevê a aplicação da punição ou penitência de acordo com o pecado cometido em vida. Consiste numa correspondência entre pena e culpa, que pode ser de vários gêneros, mas sobretudo por analogia e contraposição. Tem-se analogia quando a punição assemelha-se diretamente ao pecado, e contraposição quando as características do pecado são revertidas como sofrimento ao pecador. (PASQUAZI, citado por SARDAGNA, 2013, p. 23).

Tal lei, entretanto, não é aplicada uniformemente ao longo de toda a obra. No entrecho do Purgatório, a lei do contrapasso tem conotação distinta daquela aplicada no Inferno. Se, no Primeiro Reino, tem por função punir o vício com um sofrimento análogo inescapável, no Segundo Reino a lei tem sobretudo efeito educativo, ao instigar o treinamento da alma à plena entrega ao caminho da virtude: 
Moreover, the process of spiritual change that takes place in Purgatory is not effected, as the process of punishment is in Hell, through pain alone but rather works on the souls' sinful tendencies on a series of levels - physical, mental, and spiritual - combining the negative reinforcement of the contrapasso with positive encouragement toward virtue. [...] Purgatory is more concerned with training the souls than with punishing its vices, in each case the exempla of virtue precede those of vice. This reflects that contrast with Hell that has already been highlighted in relation to the contrapasso: the souls are not here forced to contemplate their own abjectness but instead to choose to meditate on their immediate (the specific virtue that opposes their sinful tendencies) and ultimate (God and Heaven) learning goals. (HONESS; TREHERNE, 2016, p. XVII). ${ }^{2}$

Cada alma deve encontrar na peregrinação simultaneamente a razão de sua penitência, que lhe serve de contrapasso à caminhada, e a esperança de se elevar, que lhe serve de força oposta, a persistência em caminhar. Desse modo, a geografia na qual o peregrino se desloca é semi-real (ligada ainda à terra e aos vícios corpóreos) e semi-imaginária (ligada à beleza da ascensão, que a esperança entrevê na luz e nas estrelas). No Purgatório, o termo contrapasso assume a acepção completa, simultaneamente corpórea, mental e espiritual - haja vista que no Inferno o supliciado pode apenas sentir o efeito da lei sem, contudo, manter com ela qualquer relação ativa,

\footnotetext{
2 “Além disso, o processo de mudança espiritual que ocorre no Purgatório não é efetuado, pois o processo de punição está no Inferno, não somente através da dor, mas trabalhando nas tendências pecaminosas da alma em uma série de níveis - físico, mental e espiritual - combinando o reforço negativo do contrapasso com encorajamento positivo para a virtude. [...] O purgatório está mais preocupado em treinar as almas do que em punir seus vícios, em cada caso os exemplos de virtude precedem os do vício. Isso reflete esse contraste com o Inferno que já foi destacado em relação ao contrapasso: as almas não são aqui forçadas a contemplar sua própria abjeção, mas a meditar sobre suas metas de aprendizagem imediatas (a virtude específica que se opõe a suas tendências pecaminosas) e supremas (Deus e Céu)" (tradução minha).
} 
seja refletindo sobre seu sentido, seja purificando-se, utilizando-a como guia. A plenitude da aplicação corretiva da lei do contrapasso é efetuada, sobretudo, no deslocamento do peregrino. ${ }^{3}$

Ainda que estejam condenados a permanecer longo tempo ao pé do monte, eles não perdem a esperança de serem admitidos à "[...] busca da vida verdadeira para a qual (cada um) suspira e busca em sua peregrinação" (DE SANCTIS, 1993, p. 151), enfim, ao reino da eterna beatitude. (SARDAGNA, 2013, p. 6).

Assim, pode-se dizer que peregrinar envolve o exílio voluntário. É tornar-se apátrida, isso é, sem pertencimento a qualquer localização na qual eventualmente se encontra, pois só há um único local verdadeiro, o reino eterno, para o qual se desloca física, mental e espiritualmente. O peregrino deveria enxergar, em sua caminhada, o próprio estatuto incerto de sua localização na hierarquia divina, marcada pela contradição entre forças opostas: o repouso, sob regência da lei do contrapasso e da penitência, e a passagem, ritual de esperança de recuperação do corpo glorioso e de acolhimento divino. A dialética da peregrinação consiste em, precisamente, combinar a consciência de sua localização (espera) e o sentido de seu deslocamento no interior do espaço cosmogônico (esperança). Seu caminho adquire sentido somente na conclusão do deslocamento, isto é, em efetivamente emigrar para um novo local que é, simultaneamente, real (com efeito, o purgatório é uma pena temporal - poenarum temporalium - e, conforme destacado, realiza-se de modo

\footnotetext{
${ }^{3}$ A palavra contrapasso conserva, em italiano moderno, alguma intuição do deslocamento. Originalmente contrappasso - de contrapassum (do latim contra, "oposto", e pati, "sofrer") -, o termo, atualmente, serve também para caracterizar um movimento da dança no qual dois bailarinos, logo após se afastarem, se reencontram outra vez.

Em prefácio à edição brasileira da Divina comédia, da Editora 34, Ítalo Eugênio Mauro opta por traduzir pelo termo consagrado Lei de Talião (1999, p. 12). Já nas "Notas de Leitura" que acompanham a edição da Editora Unicamp, João Adolfo Hansen opta pelo termo original, grafado em itálico (2010, p. 16) - o que deixa margem de ambiguidade com o homônimo em português, que denota, entre outras acepções, um passo dado em caminho contrário ao que se dera antes (cf. Dicionário Priberam).
} 
intimamente ligado à experiência da "vida real" do espaço e do tempo) mas, também, imaginário (o Reino dos Céus, cuja medida de aproximação se dá sobretudo por um deslocamento interior do peregrino que, mediante ação volitiva, altera a experiência do espaço e do tempo). O historiador Jacques Le Goff, ao comentar o trabalho do teólogo Boaventura também sobre a questão do Purgatório, publicado em meados do século XIII, destaca a importância da vontade na articulação da peregrinação através da esperança, da glória e do exílio da pátria.

Sobre o problema do carácter voluntário da pena do Purgatório, Boaventura pensa que ela é minimamente voluntária (minimam habet rationem voluntarii), pois a vontade "tolera-a" mas "deseja o seu oposto", quer dizer, a sua cessão e a recompensa celeste. A pergunta seguinte tem a ver com as relações entre Purgatório e Paraíso: "Haverá na pena do Purgatório menos certeza de glória do que no caminho?", quer dizer aqui em baixo, onde o homem é um viator, um peregrino? Ao que Boaventura responde: "Há mais certeza da glória no Purgatório do que no caminho, mas menos do que na pátria." Trata-se aqui do Purgatório como esperança e Boaventura vai de certa maneira além da esperança, uma vez que fala de certeza; mas introduz graus na certeza. Segue a concepção fundamental do Purgatório como "médio", intermédio, e distingue duas fases, se não dois lugares, no Paraíso: a pátria (o termo pátria e esta concepção aparecem noutros autores) que parece próxima da ideia do seio de Abraão que se encontra no repouso, e a glória que é simultaneamente a fruição da visão beatífica e, de certa maneira, a "deificação" do homem cuja alma recuperou o corpo ressuscitado e agora "glorioso". (LE GOFF, 1985, p. 297).

Retomando a teoria da heterotopia, Foucault, ao conceber uma tentativa de uma história ou arqueologia do espaço, dirá que o espaço da localização medieval somente terá fim com Galileu e a redescoberta de que a Terra gira em torno do sol. Segundo o filósofo, Galileu teria dissolvido o espaço de localização por ter concebido um "espaço infinito, 
e infinitamente aberto [...], o lugar de uma coisa não era mais que um ponto em seu movimento, exatamente como o repouso de uma coisa não passava do seu movimento infinitamente ralentado" (FOUCAULT, 2003, p. 412). Vê-se desse modo o profundo transtorno do espaço medieval. Se, na peregrinação medieval, o deslocamento adquire sentido sobretudo na passagem de um local a outro, regido por uma rígida hierarquia cosmogônica, na modernidade inaugurada por Galileu a relação de localização inverte-se, e o sujeito deve forçosamente reconhecer-se como mero "ponto" em uma linha de movimento infinita. Essa experiência radicalmente diferente do espaço pode ser percebida se compararmos a lógica do deslocamento no Purgatório e diversos relatos contemporâneos de peregrinação. Almejando marcar uma diferença explícita em relação ao mero turista, que goza apenas de maneira tópica o local em que se encontra (tornando-o, de certo modo, equivalente a todos os outros locais que pode eventualmente visitar), os devotos costumam dizer que a verdadeira experiência da peregrinação não consiste em propriamente chegar a algum local especifico (seja real, seja espiritual), mas simplesmente experienciar o próprio movimento contínuo da caminhada. O que, outrora, tinha destinação certa - ser admitido no Paraíso - converte-se numa experiência de uma fé contínua, sem paragem. Trata-se, com efeito, de uma paisagem outra, agora marcada pelo conceito de "vida" e, portanto, de "sujeito" - no interior da qual a peregrinação não faz mais que mergulhar em seu mar infinito de anthropos. Aqui, o súbito retorno espiritual ao "local" ou estágio mais elementar da fé de onde se partira já não é mais capaz de atemorizar completamente o peregrino, que passa a buscar as respostas de suas variações sentimentais única e exclusivamente em sua própria psicologia.

Escutar o meu interior, a criação que me rodeia, a Deus. [...] A solitude: estar só em sua inteireza perante o céu, a terra e o mar, perante Deus. $\mathrm{O}$ meu melhor companheiro sou eu mesmo. [...] A chegada em Santiago provoca certa depressão nas pessoas porque significa o fim de algo que deveria ser o clímax, mas não é. O mais importante é o caminhar e não o chegar. Caminhar faz parte da nossa estrutura antropológica. (MANNES, 2003, s.p. Grifos meus). 


\section{$2 \mathbf{O}$ conceito de heterotopia}

Definida a noção de espaço de localização, cumpre agora investigar qual o lugar nela ocupado pelo conceito de heterotopia.

Segundo Foucault, todo espaço seria, essencialmente, um "conjunto de relações que definem posicionamentos irredutíveis uns aos outros e absolutamente impossíveis de serem sobrepostos" (2003, p. 414. Grifos meus). Haveria, por exemplo: posicionamentos de passagem - a rua, o trem, os carros; posicionamentos de repouso - casa, quarto, leito; posicionamentos de parada provisória - cafés, cinemas, praias, etc.

Haveria, ainda, certos posicionamentos que teriam o poder de se relacionar com todos os demais posicionamentos de uma sociedade. Fundamentalmente, seriam dois: a utopia e a heterotopia. Foucault crê ser extremamente necessário destacá-los numa reflexão sobre o espaço por, justamente, serem uma espécie de analogia direta, inversa ou justaposta de todos os demais posicionamentos reais de uma determinada cultura.

As utopias seriam essencialmente posicionamentos imaginários sem lugar real; estabeleceriam, com a cultura, uma analogia direta ou inversa - seja a sociedade aperfeiçoada, seja a sociedade distópica.

As heterotopias, por sua vez, seriam lugares reais, cuja existência concreta fora estabelecida na própria instituição da sociedade. Teriam por função acolher, em seu interior, todos os demais posicionamentos da cultura através da representação, contestação e inversão. Seriam, por assim dizer, uma arquitetura reflexa, uma estrutura espelhada na qual um fino limiar separaria e conectaria o virtual com o real. O espelho, segundo Foucault, seria uma heterotopia por excelência: ao nos contemplarmos no espelho, percebemos o lugar que ocupamos com nosso corpo de modo simultâneo. De um lado, como lugar absolutamente real, nosso corpo inserido no espaço real confirmado através da imagem espelhada; e, de outro, lugar absolutamente irreal, porque nossa noção de espaço real passa a ser, agora, determinada por um ponto puramente virtual, a imagem refletida. Ao estender-se "lá longe" a imagem de nosso corpo imerso no espaço que nos circunda, o espelho nos permitiria contemplar nosso posicionamento no espaço precisamente porque elabora, através da imagem reflexa, nossa própria ausência aí convertida em presença 
puramente virtual. A imagem do espelho cria, portanto, essa espécie de espaço simultaneamente real e irreal, concreta e virtual; simula, de modo justaposto, nossa presença e ausência no espaço.

A heterotopologia - estudo dos posicionamentos heterotópicos deve identificar em um posicionamento seis princípios que determinariam seu caráter heterotópico:

1) Toda sociedade produz posicionamentos heterotópicos; entretanto, não há uma forma heterotópica universal;

2) Todo posicionamento heterotópico funciona de maneira sincrônica com a cultura, e é possível que um mesmo posicionamento heterotópico tenha função diversa em culturas diferentes (ex.: o cemitério);

3) Heterotopias têm o poder de justaposição, em um único lugar real, de vários posicionamentos reais (ex.: cinema, teatro, jardim);

4) Toda heterotopia envolve uma heterocronia; essas heterocronias estabelecem rupturas com o tempo tradicional e podem variar numa escala desde o tempo infinito (ex.: museus, bibliotecas) até o tempo precário (ex.: festas, feiras, cidades de veraneio). As heterocronias são o modo pelo qual se evoca uma espécie de saber imediato da cultura;

5) Todo espaço heterotópico possui uma estrutura de abertura e fechamento, de isolamento e penetrabilidade (ex.: ritos de purificação, motéis em rodovias norte-americanas);

6) Toda heterotopia tem, em relação ao real, uma função, que pode variar em escala desde a heterotopia de ilusão, aquela que denuncia como mais ilusórios ainda todos os demais espaços reais (ex.: bordel), até a heterotopia de compensação, espaço meticulosamente organizado na proporção inversa à desordem do espaço real (ex.: colônias de jesuítas).

Segundo Foucault (2003), caberia à heterotopologia tipificar e classificar os posicionamentos heterotópicos e investigar o modo como funcionam, para uma determinada cultura, como uma espécie de reserva inesgotável de imaginação, isto é, um espaço no qual a civilização logra exercitar a perpétua metamorfose dos posicionamentos reais mediante um intenso exercício de virtualização de todo espaço possível. O barco, 
para o autor, seria o posicionamento heterotópico por excelência. Seria uma espécie de "espaço flutuante, lugar sem lugar" (p. 421), portanto, simultaneamente real e virtual, lá onde no mar sua imagem se perde das vistas. É fechado em si; porém, simultaneamente, fora lançado ao infinito das águas. Cruzando os estreitos marítimos e abarcando "de porto em porto, de escapada em escapada para a terra, de bordel a bordel" (p. 421), os barcos colheriam e presenteariam cada colônia com o que haveria de mais precioso em seus jardins. $\mathrm{O}$ barco seria não apenas $\mathrm{o}$ maior instrumento de desenvolvimento econômico, mas também "a maior reserva de imaginação. O navio é a heterotopia por excelência. Nas civilizações sem barcos os sonhos se esgotam, a espionagem ali substitui a aventura, e a polícia, os corsários” (p. 422).

\section{Os caminhos de Compostela}

Para nossa heterotopologia da peregrinação, elegeremos o caminho de Compostela, dedicado ao grande Apóstolo da Galícia, São Tiago, como recorte. Aqui, faremos uma breve revisão histórica desse momento.

A peregrinação jacobeia tem início por volta dos anos de 820-830, com a peregrinação do rei Alfonso II, o Casto, e sua corte asturiana até o achado do sarcófago de São Tiago na Galícia, extremo ocidente da Europa (SINGUL, 1999, p. 54). O auge da peregrinação a Compostela se dá no século XII (p. 83). Entre os diversos motivos do surgimento do fenômeno da peregrinação à tumba apostólica está o culto àquele que havia pregado na Espanha - "Jacobus, filius Zebedei, ... hic Spaniae et occidentalia loca predicavit" - e contribuído com sua santidade no combate às forças do Islão andaluz. Os povos da Europa altomedieval eram simpáticos com o Reino das Astúrias porque haviam vencido os muçulmanos em uma luta desigual e configurado, assim, uma rota segura aos confins ocidentais. A descoberta e construção do Locus Sanctus jacobeu significara, para o homem europeu, a esperança devota e piedosa de uma vida renovada através da visita a uma "terra virgem, santa e despolitizada, na qual tinham muito a ganhar e nada a perder” (SINGUL, 1999, p. 54). 
A peregrinação a Santiago de Compostela fora um fenômeno extremamente complexo. Diversas fontes do século XII dão conta da presença de uma multiplicidade de povos e verdadeiros movimentos de massa:

Todos os povos, de todas as raças e de todas as condições estão presentes, tanto nos caminhos, como na própria cidade de Compostela. Tal afirmação, ainda que pareça hiperbólica aos nossos olhos, nos revela a extensão e densidade da devoção a São Tiago. (DYAZ Y DYAZ, 1992, p. 133).

O poder de intercessão de São Tiago é bastante vasto e um semnúmero de milagres lhe são atribuídos pelos peregrinos jacobeus. Assim diz o Liber Sancti Jacobi, ou Codex Calixtinus, uma espécie de compêndio de milagres e guia de peregrinação a Santiago de Compostela, do século XII:

A saúde é dada aos doentes, a vista é devolvida aos cegos, a língua dos mudos é desatada, a audição é concedida aos surdos, um andar normal é dado aos coxos, os possessos são libertados, as preces dos fiéis são atendidas, suas promessas são cumpridas, as cadeias do pecado se rompem, o céu se abre aos que o procuram, o consolo é dado aos aflitos. (FRANCO JR., 1999, p. 86).

Segundo Franco Jr. (1999, p. 86), São Tiago era invocado nas mais diversas circunstâncias: "prisioneiros ou escravizados pediam para ser libertados, mulheres para engravidar, pessoas caídas ao mar para retornarem ao navio ou serem levadas salvas para a terra. Poderosos pediam para ser ajudados em batalha". Os peregrinos elencados por São Tiago em seus milagres são, em primeiro lugar, os pobres; em segundo, os doentes - diz o Liber Sancti Jacobi (p. 103): "humilha os poderosos, enaltece os humildes, ama a pobreza [...], refúgio dos pobres, fortaleza dos fracos, consolo dos atribulados, salvação dos peregrinos".

A via peregrinalis é uma via estreita, de difícil acesso, que exigirá do peregrino o "controle do corpo e das paixões corporais (do ventre pela redução das refeições, e dos prazeres carnais), além das outras paixões (como, por exemplo, a avareza), a purificação do espírito, o que leva à 
humildade e à pobreza" (DYAZ Y DYAZ, 1992, p. 136). Antes, durante e depois de sua jornada, cada peregrino deve:

pagar suas contas, perdoar eventualmente seus devedores, e colocar em ordem e em paz sua família, seus vizinhos, seus dependentes que permanecem no lugar. E mais ainda, deve distribuir seus bens supérfluos entre os pobres; fazer-se perdoar por todos aqueles que sofreram suas injustiças; deve prometer enfim que ele os tratará com mais generosidade, mais justiça, mais caridade, a partir de seu retorno de Compostela. (DYAZ Y DYAZ, 1992, p. 139).

O homo peregrinus é, portanto, aquele que, em uma espécie de exílio voluntário - inspirado por aqueles que serviram a Cristo - , segue em busca de sua verdadeira pátria, o reino celestial (DYAZ Y DYAZ, 1999, p. 417). O historiador Ivo Correia de Melo Neto (2010, p. 54) estabelece os tipos de peregrinação: votiva, em agradecimento por uma graça recebida; penitencial, por punição a algum pecado cometido; de livre vontade, como exercício de ascese e devoção; e sanativa, em busca da cura. Somente a peregrinação sanativa, isto é, em busca do milagre, não teria sido "oficialmente" permitida, embora fosse amplamente tolerada.

As rotas até Compostela podiam ser feitas pela terra, desde a França, ou pelo mar, a rota preferencial dos ingleses. O livro V de Liber Sancti Jacobi destaca quatros grandes caminhos da França até a terra jacobeia: Paris, Vezelay, Le Puy e Arles (DE AGUIRRE, 2016, p. 177). Com o tempo, as rotas ofereciam uma estrutura completa à peregrinação. Destaca ainda o Liber Sancti Jacobi as múltiplas funções da igreja: culto a outros santos, abrigo de relíquias, dispor de hospitalidade aos viajantes, e, também, "igrejas-funerárias", onde jaziam tanto os corpos de peregrinos que morreram em jornada, como também corpos santos:

Estos tres hospitales están colocados en sitios necesarios; son lugares santos, casas de Dios, reparación de los santos peregrinos, descanso de los necesitados, consuelo de los enfermos, salvación de los muertos, auxilio de los vivos. Así 
pues, quienquiera que haya edificado estos lugares sacrosantos poseerá sin duda alguna el reino de Dios. (DE AGUIRRE, 2016, p. 182). ${ }^{4}$

Havia também uma complexa regulamentação da peregrinação. Cada devoto deve, antes de partir, confessar-se; obter a permissão do sacerdote, e, em alguns casos, a autorização do cônjuge. Havia, também, uma lex peregrinorum, que regulamentava a prática da peregrinação, consistindo basicamente de benefícios, isenções fiscais e direitos quanto à disposição testamentária para caridade. Os monarcas, por sua vez, também favoreciam o afluxo de peregrinos com isenção de tributos, garantias comerciais e punições severas àqueles que furtassem o caminhante. A igreja adotava, através do direito canônico e de resoluções conciliares, posições em favor da peregrinação - como excomungação de molestadores e espoliadores de peregrinos, liberdade para que peregrinos circulassem por todo o território espanhol, benefícios fiscais a hospitais que ocupavam a rota compostelana (FRANCO JR., 1990, p. 107), e, ainda, indulgências de graça e perdão aos peregrinos (LEÃO, 2007, p. 84). A mera posse da concha jacobeia (símbolo consagrado ao peregrino que comprovadamente chegara até Compostela) era, muitas vezes, suficiente para localizar o indivíduo sob a lex peregrinorum. $\mathrm{O}$ historiador Piotr Roszak localiza a importância dos caminhos de Santiago para uma primeira experiência de uma espécie de "lei internacional especificamente, a proteção legal do peregrino (ius peregrinandi) foi a gênese dos esforços transnacionais de proteção e garantia de segurança da translação" $\left(2015\right.$, p. 647)..$^{5}$

\footnotetext{
4 "Estes três hospitais estão localizados em lugares oportunos; são lugares santos, casas de Deus, reparação dos santos peregrinos, descanso dos necessitados, consolação dos doentes, salvação dos mortos, ajuda dos vivos. Assim, quem quer que tenha construído esses lugares sacrossantos, sem dúvida possuirá o reino de Deus" (tradução minha). ${ }^{5}$ No original, "an international law - specifically, the legal protection of pilgrims (ius peregrinandi) was the genesis of transnational efforts to guarantee the safety of movement" (tradução minha).
} 


\section{A heterotopia da peregrinação}

Com efeito, uma análise heterotopológica da peregrinação jacobeia permite-nos identificar as características gerais e os seis princípios da heterotopia.

Primeiro, a peregrinação a Santiago de Compostela está, sob diversos aspectos, relacionada a todos os demais posicionamentos reais da cultura medieval. Isto pode ser verificado em dois aspectos cruciais. Primeiro, a universalidade do poder de intercessão de São Tiago superado apenas por Santa Maria, conforme atestam as Cantigas de Santa Maria. Em oposição aos santos especialistas em interceder por certas necessidades ou enfermidades específicas, São Tiago tem poder tanto da cura, da natalidade, do resgate, da expurgação dos vícios e do mal, quanto da guerra, simbolizado por Santiago Matamouros. Segundo, o fato de que a peregrinação requer a conversão do homo peregrinus em um homem piedoso capaz de transformar a totalidade de suas atitudes cotidianas, tendo em vista a vida verdadeiramente digna do reino dos céus. Desse modo, a experiência da peregrinação requer a consciência - e transformação - da totalidade dos posicionamentos reais cotidianos.

Além disso, a peregrinação interliga o lugar real com outro lugar reflexo, virtual. Pois - e a peregrinação sanativa, aquela que parte em busca do milagre, simultaneamente proibida e tolerada pela igreja, não nos deixa dúvidas - é o espaço por excelência da ocorrência do miraculoso. Tratase, com efeito, de um lugar real, localizado concretamente no espaço, e que, entretanto, está apto, como toda heterotopia, a presentificar e justapor posicionamentos virtuais, irreais e imaginários, seja através da miraculosa purificação espiritual, seja através da intercessão de milagres divinos.

De que modo se formaria o virtual na peregrinação? Segundo Jacques Le Goff, o milagre estaria intimamente ligado ao maravilhoso; e é numa espécie de "mundo às avessas, mundo ao contrário, distinção entre o miraculosus, o magicus, o mirabilis" (LE GOFF, 1985, p. 27) que o miraculoso adquiriria seu profundo sentido. Toda peregrinação é uma heterotopia de compensação na medida em que é "evidente a função de compensação do maravilhoso. O maravilhoso é um contrapeso 
à banalidade e regularidade do quotidiano [...], uma espécie de universo virado ao contrário" (LE GOFF, 1985, p. 26).

O maravilhoso conserva estreita relação etimológica com o espelho, a mais pura heterotopia na visão de Foucault. O termo mirabilia tem por raiz mir (miror, mirari) e trata de algo da ordem do visivo: é uma manifestação do olhar. É possível aproximar, segundo o léxico do Ocidente medieval, os termos mirari, mirabilia ("maravilha") com miroir ("espelho"; o francês conserva, portanto, o parentesco com a origem em latim) (LE GOFF, 1985, p. 20). Mirabilis seria, segundo Le Goff, a manifestação do maravilhoso em toda sua potência sobrenatural e de origem pré-cristã, e reflete, através do inapreensível que sua aparição emana, a própria precariedade do cotidiano. A mirabilis se desdobraria em duas outras manifestações, que o autor identifica em polos específicos da cosmologia cristã: a manifestação do magicus seria o "sobrenatural maléfico, o sobrenatural satânico"; já a manifestação do miraculosus seria a outra parte do mirabilis, uma espécie de "maravilhoso cristão" (LE GOFF, 1985, p. 24), ao passo que miraculum, o milagre, seria um dos diversos eventos possíveis do miraculosus.

Segundo Le Goff, a ocorrência do milagre racionalizaria o maravilhoso ao mesmo tempo em que seria saturado por ele. Ou seja, o milagre seria, ao mesmo tempo, uma espécie de crítica do maravilhoso e sua manifestação concreta. Ao consagrar aos santos o poder de interceder pelo homem junto ao arbítrio de Deus, o milagre despojaria o maravilhoso de um de seus aspectos fundamentais: a imprevisibilidade. A doutrina cristã requer que o fenômeno do milagre se inscreva em uma situação prevista - que contenha certos gestos e símbolos previamente enumerados -, para que se possa comprovar sua ocorrência. Entretanto, segundo a historiadora Mercedes Brea, nas Cantigas de Santa Maria (códice composto em galegoportuguês no período por Afonso $\mathrm{X}$, onde são descritos diversos milagres intercedidos a peregrinos), sempre algo do maravilhoso insistiria no milagre à força de uma imprevisibilidade pré-cristã que causaria "se não terror, ao menos temor" (BREA, 1993, p. 61).

A relação com o maravilhoso pode ser pressentida no modo distinto como se articula o seu fracionamento nas formas mágicas e miraculosas. O diabo, manifestação mágica, pode assumir diversas cores 
- negro (noite, morte), verde (islã), azul ou violeta (natureza inferior), marrom ou cinza pálido (enfermos e mortos), roxo (chamas e sangue) - e formas grotescas - deformada, mas humana, humanoide, bestial (BREA, 2012, p. 111); nada podendo, entretanto, determinar a priori a forma como irá se apresentar ao homem. A diversidade iconográfica do diabo não tem correspondência na imagem dos santos, cujo repertório é comparativamente mais restrito. São Tiago, por sua vez, é representado em três formas fixas - apóstolo, cavaleiro e peregrino - e a evolução de sua iconografia é bem marcada historicamente (TORRAS, 2012). Haveria certa previsibilidade acerca da imagem e dos gestos dos santos, e Le Goff chega, inclusive, a apontar certo cansaço do homem medieval diante de tal previsibilidade:

[...] temos depois uma regulamentação do maravilhoso no milagre. Temos simultaneamente um controlo e uma crítica do milagre que, no limite, faz desvanecer o maravilhoso, e por fim temos aquilo a que eu chamo uma tendência para racionalizar o maravilhoso e em particular para despojá-lo mais ou menos de um caráter que me parece essencial, a imprevisibilidade. [...] Desde que se encontre numa determinada situação, sabe-se logo que procederá a uma multiplicação dos pães, que operará uma ressurreição, que expulsará um demônio. Dada a situação, já se sabe o que irá acontecer. Temos assim um processo de esvaziamento do maravilhoso. (LE GOFF, 1985, p. 25).

Porém, há situações na peregrinação que põem em xeque a previsibilidade e a racionalização do maravilhoso; e a peregrinação é por excelência o espaço de exercício in loco da distinção perceptiva entre o maravilhoso, o miraculoso e o mágico. O milagre narrado no capítulo XVII do Livro II do Liber Sancti Jacobi permite elucidar melhor as distinções entre o maravilhoso, o miraculoso e o mágico; bem como compreender de que modo se formam as justaposições de posicionamentos reais na imagem virtual da heterotopia de peregrinação. Trata-se da historia do peregrino Giraldo, um peleteiro da região de Lyon que tinha por hábito ir anualmente a Compostela em peregrinação votiva. Vivia de maneira casta 
e solitária com sua mãe; porém, logo no dia anterior ao início de mais uma jornada jacobeia, fornica com uma jovem; desse modo, sem confessarse, parte em pecado para sua peregrinação. Durante seu caminho, vê surgir a figura de São Tiago, que o recrimina por ter peregrinado sem se confessar, e, antes mesmo que pudesse decidir regressar para readquirir a graça, São Tiago aparece uma segunda vez, admoestando-o que tal intenção não bastava e que, caso pretendesse se salvar, deveria cortar fora as partes com as quais pecara. Giraldo, embora argumente que o suicídio era também pecado, opta por castrar-se logo após ter sido tranquilizado pelo Santo, que garantira interceder por sua alma junto aos céus. Um verdadeiro devoto de São Tiago, porém, deveria ter desconfiado desde o primeiro momento daquela figura - pois tratava-se, em verdade, do demônio travestido de Santo, trazendo a tentação do suicídio. Mercedes Brea (2012, p. 117) nota que, nas iluminuras contidas na primeira parte do códice T.I.1 del Monasterio del Escorial, que contém a primeira metade das Cantigas de Santa María, o artista subtraíra da aparição demoníaca o halo de santidade que identifica São Tiago nas outras representações. O halo é, precisamente, aquele excesso luminoso que, saturando a imagem divina, representa o divino maravilhoso. Desse modo, o elemento mais expressivo que permite distinguir o miraculoso do mágico é, justamente, um aspecto da intensa fulguração do mirabilis. Os desdobramentos da história do peleiro Giraldo terminam pela intercessão positiva de São Tiago e Santa Maria em favor do peregrino, que terá a vida restituída (ainda que, no lugar dos genitais extirpados, tenha surgido apenas uma verruga através da qual Giraldo urinava; BREA, 2012, p. 115).

Este relato de milagre permite-nos explicitar dois outros aspectos heterotópicos da peregrinação. Primeiro, a estrutura de abertura e fechamento, isolamento e penetrabilidade, da rota de peregrinação. Conforme descrevemos, há uma série de regras e dogmas que devem ser estritamente seguidos para que se possa adentrar o lugar altamente regulado da peregrinação. Para partir, o peregrino deve resolver todas suas pendências terrenas, confessar-se e obter a benção, e ter em mente que somente terá concluído sua peregrinação caso tenha se convertido integralmente em um homem piedoso, que deverá relacionar-se de modo completamente diferente com sua sociedade. Giraldo, ao fornicar em 
pecado uma garota e infringir desse modo as regras, torna incerto não apenas o estatuto de sua peregrinação, mas também o de sua vida pregressa, até então supostamente conduzida de modo devotado. O demônio se aproveita da situação para agir através de uma curiosa inversão da função de compensação da peregrinação: se peregrinar envolve, essencialmente, uma compensação da miséria cotidiana através da expurgação dos pecados e dos vícios, o demônio insta o peregrino a compensar pelo modo contrário, através da execução de um pecado ainda mais grave, o suicídio. Vê-se, desse modo, que o posicionamento real da fornicação está implicado em dois pontos virtuais justapostos: o da purificação e o da tentação. O milagre da intervenção de São Tiago e Santa Maria - mas também a verruga que brotara no local do pecado - é o modo manifesto como se refletem de modo visivo todos os demais posicionamentos reais - o ofício de peleteiro, a vida casta, a casa da mãe, o corpo da moça, a devoção, etc. - no interior do espaço heterotópico da peregrinação.

A heterocronia da peregrinação é a do tempo infinito. Ao deslocarse até a morada eterna, o peregrino quer libertar-se da precariedade do tempo cotidiano. Ao inverter o fluxo cotidiano do tempo, o peregrino tem acesso a essa espécie de, conforme enunciara Foucault, saber imediato da heterocronia. É nesse sentido, sobretudo, que se deve compreender a longa dimensão temporal que o ato de caminhar até a terra santa envolve (dimensão que, na Divina comédia, recebia sentido máximo na pena temporal do Purgatório). A caminhada é, a exemplo do mártir, a própria crispação do corpo perante o tempo eterno; o corpo, ligado à terra, testemunha a eternidade através da fadiga e do cansaço, e somente será assegurada a vida eterna àqueles que perseverarem no caminho, pois têm esperança. A lei do contrapasso, tal qual elaborara Dante, contrasta o tempo precário da vida cotidiana com aquele, leve, do tempo eterno. Se a geografia terrestre é acidentada, repleta de risco, a luz que emana do dia e das cousas belas, e o caminho orientado pelas estrelas, é a promessa de eterna beatitude. Conforme relata o Codex Calixtinus, o Caminho de Santiago é, também, a Via Láctea, através da qual o peregrino pode orientar-se rumo a Compostela, isto é, ao campo de estrelas. 
A peregrinação é, assim como o barco destacado por Foucault, uma espécie de espaço flutuante, lugar sem lugar. Não apenas as rotas marítimas, mas também as terrestres, abrem, em plena geografia terrestre, o espaço infinito do campo de estrelas, território de transmutação miraculosa do espaço e do tempo. $\mathrm{O}$ barco e a peregrinação estão entremesclados em uma imagem central da arqueologia do saber e da loucura. Trata-se da Narrenschiff, a nau de loucos que, desde a Idade Média, levavam de uma cidade a outra os insanos:

É possível que essas naus de loucos, que assombraram a imaginação de toda a primeira parte da Renascença, tenham sido naus de peregrinação, navios altamente simbólicos de insanos em busca da razão [...]. É para o outro mundo que parte o louco em sua barca louca; é do outro mundo que ele chega quando desembarca. Essa navegação do louco é simultaneamente a divisão rigorosa e a passagem absoluta. Num certo sentido, ela não faz mais que desenvolver, ao longo de uma geografia semi-real, semi-imaginária, a situação liminar do louco no horizonte das preocupações do homem medieval. (FOUCAULT, 1978, p. 15-16).

A peregrinação goza, também, de situação liminar: o acesso regulado à peregrinação cumpre, efetivamente, garantir a partida irrestrita ao "outro mundo"; e o retorno do peregrino à sua cidade natal é, também, o retorno daquele doravante estrangeiro, que deve conservar-se na mais estrita caridade e bem-aventurança.

Por fim, pode-se elencar como uma das funções do espaço heterotópico da peregrinação a progressiva racionalização da geografia da Europa - através, sobretudo, da lex peregrinorum. É somente na Idade Clássica, com o advento dos Estados modernos, que esse direito será revogado, mediante exigência de diversas permissões oficiais - como as disposições reais de Luís XIV de 1671 e 1687 (SINGUL, 1999, p. 62) e aquelas exigidas pela Coroa Inglesa às naus de peregrinos. Isto, 
entretanto, não diminuirá a importância do Caminho de Santiago como "a mais longa rua da Europa" (ROSZAK, 2015, p. 650). ${ }^{6}$

O marco regulatório da peregrinação, acompanhado de intensa circulação em massa de povos de diversas origens, pode ser compreendido, conforme sugere o historiador Piotr Roszak (2015, p. 48), como uma origem arqueológica da zona de Schengen, que unirá as fronteiras comuns dos 26 Estados da União Europeia. Entretanto, se é o caso de aproximarmos o Caminho de Santiago da União Europeia, vale a pena indagar de que modo esta se relacionará com o seu entorno. Pois, se a rota jacobeia fora fundamentada a partir da guerra contra o islã, tal fato não impediu que se entrevisse São Tiago, ainda Matamouros, interceder com um milagre em benefício de um muçulmano: “[...] narrado pela Historia Compostelana, e que teria beneficiado um muçulmano, curando-o de um abscesso no pescoço, pois ele reconhecia que o apóstolo estava sempre pronto a favorecer "quantos lhe imploram ajuda"' (FRANCO JR., 1990, p. 105-106).

\section{Conclusão}

Buscamos, ao longo do artigo, demonstrar que a análise heterotopológica da peregrinação - em especial, do Caminho de Santiago - pode ajudar a compreender de que modo o fenômeno da peregrinação se relaciona com o espaço de localização medieval. Além disso, pode servir como ponto de inflexão para o aprofundamento da arqueologia da loucura e da razão ocidental. A sobrevivência da peregrinação como forma contemporânea de devoção também pode ser explorada através do conceito de heterotopia, destacando-se assim as funções sincrônicas diversas que uma mesma forma - o ato de peregrinar - recebera ao longo da história. Por fim, destaca-se a importância de se investigar de que modo a peregrinação contribuiu para a racionalização da geografia - em especial, a europeia -; e também se há uma possível relação entre a atual zona de Schengen e a peregrinação jacobeia.

${ }^{6}$ No original, "the longest street in Europe" (tradução minha). 


\section{Referências}

BREA, M. Demonios travestidos de santos: el caso del peregrino engañado por Satanás. In: PAREDES, J. (ED.). De lo humano y lo divino en la literatura medieval: santos, ángeles y demonios. Granada: Editorial Universidad de Granada, 2012. p. 109-122.

BREA, M. Milagros prodigiosos y hechos maravillosos en las Cantigas de Santa Maria. Revista de Literatura Medieval, Alcalá de Henares, v. V, p. 47-61, 1993.

DANTE, A. Divina comédia: Purgatório. Tradução de Ítalo Eugênio Mauro. São Paulo: Editora 34, 1999.

DE AGUIRRE, J. M. Una arquitectura del Camino de Santiago: los binomios hospital-iglesia funeraria entre los Pirineos y la Meseta (1150-1220). In: GARCÍA DE CORTÁZAR, J. Á.; TEJA, R. (Ed.). Los monasterios medievales en sus emplazamientos: lugares de memoria de lo sagrado. Aguilar de Campoo: Fundación Santa María La Real del Patrimonio Historico, 2016. p. 175-211.

DYAZ Y DYAZ, M. Interprétations du pèlerinage jacobèen: les traces du pèlerinage à Saint-Jacques-de-Compostelle dans la culture européenne. Patrimoine Culturel, Estrasburgo, v., n. 20, p. 3-7, 1992 (material traduzido e disponibilizado por Viviane Cunha).

DYAZ Y DYAZ, M. Las Peregrinaciones y la peregrinación a Santiago. CONGRESO DE ARQUEOLOGÍA MEDIEVAL ESPAÑOLA, 5., 1999 , Valladolid. Actas... Valladolid: Junta de Castilla y Léon, 2001. v. 1. p. 417-422.

FOUCAULT, M. Outros espaços. In: - Ditos e escritos. Estética: literatura e pintura, música e cinema. Rio de Janeiro: Forense Universitária, 2003. p. 411-422.

FOUCAULT, M. Stultifera Navis. In: Idade Clássica. São Paulo: Perspectiva, 1978. p. 3-44.

. História da loucura na

FRANCO JR., H. Os peregrinos, transmissores de práticas religiosas e sociais. In: . Peregrinos, monges e guerreiros: feudo-clericalismo e religiosidade em Castela medieval. São Paulo: Hucitec, 1990. p. 83-112.

HANSEN, J. A. Notas de leitura. In: DANTE, A. Divina comédia. Tradução de João Trentino Ziller. Campinas: Editora da Unicamp, 2010. p. 9-58 
HONESS, C. E.; TREHERNE, M. Introduction. In: DANTE, A. Purgatorio. Indianapolis: Hackett Publishing, 2016. p. viii-xxxviii

LE GOFF, J. O maravilhoso e o quotidiano no ocidente medieval. Lisboa: Edições 70, 1989.

LE GOFF, J. O nascimento do Purgatório. Lisboa: Editorial Estampa, 1985.

LEÃO, Â. V. Cantigas de Santa Maria de Afonso X, o Sábio: aspectos culturais e literários. Belo Horizonte: Veredas \& Cenários, 2007.

MANNES, P. Q. Relatos e reflexões sobre o caminho de Santiago. Disponível em: <http://amigosdocaminho.com.br/relatos-e-reflexoessobre-o-caminho-de-santiago/>. Acesso em: 3 set. 2016.

DISTANTE, C. Prefácio. In: DANTE, A. Divina comédia: Purgatório. Tradução de Ítalo Eugênio Mauro. São Paulo: Editora 34, 1999. p. 7-17.

NETO, I. C. de M. Peregrinos y santuarios en las cantigas de Santa María. Temas Medievales, Buenos Aires, v. 18, p. 47-72, 2010.

ROSZAK, P. The "Prelude" to the Camino. The Way of St. James and the Cultural Identity of Kuyavia e Pomerania. Compostellanum: Revista de la Archidiócesis de Santiago de Compostela, Santiago de Compostela, v. 60, n. 3-4, p. 645-653, 2015.

SARDAGNA, C. A. Leitura do Purgatório da Divina comédia: o cenário, uma mulher e a procissão no paraíso terrestre. 2006. 134 f. Dissertação (Mestrado em Literatura) - Centro de Comunicação e Expressão, Universidade Federal de Santa Catarina, Florianópolis, 2006.

SINGUL, F. O Caminho de Santiago. Rio de Janeiro: EDUERJ. 1999

TORRAS, B. F. Do apóstolo ao peregrino: a iconografia de São Tiago na escultura devocional medieval em Portugal. Medievalista, v. 12, 2012. Disponível em: <http://medievalista.revues.org/624>. Acesso em: 12 jun. 2016.

Recebido em: 15 de maio de 2018. Aprovado em: 29 de outubro de 2018. 